Article

\title{
A News Big Data Analysis of Issues in Higher Education in Korea amid the COVID-19 Pandemic
}

\author{
Jangwan Ko ${ }^{1}$, Seungsu Paek ${ }^{2, *}$, Seoyoon Park ${ }^{1}$ and Jiwoo Park ${ }^{1}$ \\ 1 College of Education, Sungkyunkwan University, Seoul 04063, Korea; jakosu@skku.edu (J.K.); \\ pseoyoon@skku.edu (S.P.); jiwoopark1993@gmail.com (J.P.) \\ 2 Graduate School of Education, Gachon University, Seongnam 13120, Korea \\ * Correspondence: ongang@gachon.ac.kr; Tel.: +82-31-750-8625
}

check for updates

Citation: Ko, J.; Paek, S.; Park, S.; Park, J. A News Big Data Analysis of Issues in Higher Education in Korea amid the COVID-19 Pandemic. Sustainability 2021, 13, 7347. https:/ / doi.org/10.3390/su13137347

Academic Editor: Miltiadis (Miltos) Alamaniotis

Received: 26 May 2021

Accepted: 28 June 2021

Published: 30 June 2021

Publisher's Note: MDPI stays neutral with regard to jurisdictional claims in published maps and institutional affiliations.

Copyright: (c) 2021 by the authors. Licensee MDPI, Basel, Switzerland. This article is an open access article distributed under the terms and conditions of the Creative Commons Attribution (CC BY) license (https:// creativecommons.org/licenses/by/ $4.0 /)$.

\begin{abstract}
This paper examines the main issues regarding higher education in Korea-where college education experienced minimal interruptions-during the COVID-19 pandemic through a big data analysis of news articles. By analyzing policy responses from the government and colleges and examining prominent discourses on higher education, it provides a context for discussing the implications of COVID-19 on education policy and what the post-pandemic era would bring. To this end, we utilized BIgKinds, a big data research solution for news articles offered by the Korea Press Foundation, to select a total of 2636 media reports and conducted Topic Modelling based on LDA algorithms using NetMiner. The analyses are split into three distinct periods of COVID-19 spread in the country. Some notable topics from the first phase are remote class, tuition refund, returning Chinese international students, and normalization of college education. Preparations for the College Scholastic Ability Test (CSAT), contact and contactless classes, preparations for early admissions, and supporting job market candidates are extracted for the second phase. For the third phase, the extracted topics include CSAT and college-specific exams, quarantine on campus, social relations on campus, and support for job market candidates. The results confirmed widespread public attention to the relevant issues but also showed empirically that the measures taken by the government and college administrations to combat COVID-19 had limited visibility among media reports. It is important to note that timely and appropriate responses from the government and colleges have enabled continuation of higher education in some capacity during the pandemic. In addition to the media's role in reporting issues of public interest, there is also a need for continued research and discussion on higher education amid COVID-19 to help effect actual results from various policy efforts.
\end{abstract}

Keywords: news big data; higher education; LDA; COVID-19; online education; South Korea

\section{Introduction}

Almost all countries suffered from the COVID-19 pandemic in 2020. Economies ground to a halt, and social relations were severed. Not unlike other areas, the education sector had its own share of challenges induced by the spread of the disease [1-3]. Schools were closed, classes had to be modified or cancelled, and online classes became the new norm. Students and their parents experienced difficulties adjusting to the new format of education, and instructors had to learn new technologies to teach classes effectively. The government and college administrations had to make a difficult choice between continued education and quarantine, and they modified pre-existing policies and enacted new ones to combat the pandemic. Despite these efforts, a majority of people working in the education sector voiced doubts about the efficacy of the newly-imposed measures.

From the outbreak of COVID-19 in January 2020, numerous studies have examined COVID-19 and higher education. Although these studies have been conducted in a wide variety of fields, studies on online and distance education and the health and psychological 
status of students and professors have been dominant. That is, in a situation where faceto-face classes had to be switched to online because of the sudden outbreak of COVID-19, the discussion on the implementation of effective online education was dominant [4-12]. Other than online education, numerous studies on university life and the health and psychological status of students and professors have been dominant [13-17]. Furthermore, some studies have been conducted to analyze higher education in the COVID-19 situation from the perspective of professors rather than the student perspective $[10,18,19]$.

However, despite their merits, these studies have shown limitations primarily for not addressing macro-level analyses. There is a limit to the analysis of how the government's policy, implemented regulations, and universities responded. For example, the systematic analysis of government policies in response to the outbreak, association of government policies with university responses, and in-depth analysis of university financial problems because of COVID-19 have been limited. Some studies have addressed this aspect. For example, a study analyzing the case of South Africa [20] specifically described the national response and responses of the Department of Higher Education and Training, including funding higher education; reopening of campuses; and contents of the university's response, such as teaching, learning, and research activities. A study that analyzed the systemic simulation of the financial difficulties of universities [21] is also beneficial because it can offer implications on the roles and efforts of the government and universities in crisis management during the COVID-19 pandemic. Nevertheless, few studies have examined the role of the government and the response of universities in these macroscopic aspects. The analysis of macroscopic aspects is necessary because it can dynamically show aspects of higher education and the social environment surrounding higher education.

Although Korea had to grapple with similar issues, an array of effective quarantine measures and other policies prevented interruptions to higher education. News outlets praised the successful government response in limiting the damage of the pandemic to both the country in general and to the education sector. However, there has been a scarcity of in-depth discussion, especially within the academic community, on whether it is indeed the case.

Among the limited number of researches on this matter, most have focused on narrow, specific aspects of education. Some of the subjects addressed by existing research include online education in the COVID-19 era [22-24], issues regarding potential refund of tuition given the preponderance of remote education [25], and securing the inflow of international students [26], but there has been no attempt at identifying a comprehensive list of issues that emerged following the pandemic. The only exception was a study in the area of secondary education where the researchers examined the struggles of the instructors amid COVID-19 through media reports and made policy recommendations for raising a new generation of teachers [27]. In light of this study, there is a need for a comprehensive analysis of general issues related to COVID-19 in higher education as well.

While some countries are bringing infection rates under control with the introduction of vaccines, the COVID-19 pandemic that swept across the globe in the last year continues to ravage many others, making a return to pre-pandemic normalcy a distant prospect. The same holds for Korea, where there has been a steady stream of new cases despite vaccination efforts. As of now, it is unclear whether the government will be able to normalize on-campus college education from the upcoming Fall semester as it plans.

With these facts in mind, this paper aims to identify the main issues regarding higher education in Korea during the pandemic through a big data analysis. By examining the government and college-level responses as well as the discourses that surfaced during several different phases of COVID-19 spread, the paper sheds light on the implications of these issues on education policy and provides a context for discussing the post-pandemic era. 


\section{Spread of COVID-19 and Responses of the Education Sector in Korea}

\subsection{COVID-19 and Higher Eduction in the World}

The year 2020 was a period of chaos and confusion caused by the COVID-19 outbreak, and higher education was no exception. Nevertheless, countries and universities worldwide have made various efforts to overcome this. Discussions regarding various problems caused by the COVID-19 outbreak and the responses of countries and universities have occurred individually in terms of countries or universities. For example, not only European countries, such as the United Kingdom [28], Germany [29], Italy [30], and Spain [18], but also Asian countries such as China [31], the Philippines [32], and Malaysia [33], as well as South American [34] and South African [19] countries, have reported the overall impact on universities brought caused by the COVID-19 pandemic, namely, concerns regarding difficulties in university education, university life in a state of uncertainty, and administrative and financial difficulties for university operation.

When considering the cases of each country responding to COVID-19, the common, major concern is online education and/or distance learning. That is, in the early days, various efforts were focused on how to do well in online education with the COVID-19 outbreak. Numerous countries worldwide had already started school in mid-January 2020, and with the spread of COVID-19 during the reopening after lockdown, emergency measures had to be taken to respond to COVID-19. In addition to campus quarantine, replacing the existing face-to-face education with online education was common. In particular, because universities were unable to conduct normal classes, plans for Emergency Remote Teaching had to be discussed. ERT is not a normal online education but is to be used an emergency situation while maintaining the education content used in the existing faceto-face education, changing only the delivery method. In particular, rather than considering the educational effect, the class is conducted using a device that was available at the time. An early case of ERT operation is shown in a study conducted at a Spanish university from March to June, 2020, during the early stages of the outbreak [4]. This ERT was not unique to Spain but a phenomenon common to most countries [28,35,36]. As COVID-19 continued and universities started offering online lectures, numerous discussions took place [5-9]. Almost all universities, whether prerecorded lectures or real-time lectures, are conducting full online lectures for the first time, and thus, they were forced to come up with an active response plan. The same was true for professors and students. Professors had to learn how to efficiently and effectively deliver lecture content and how to use devices for this purpose, and it was important for students to learn effective learning methods for online lectures [10-12].

Online education was not the only problem. Campus life and social life (e.g., closed campus, no physical relationships, and no traveling) as well as adaptation and response [13-16] of students changed because of COVID-19 and the related emotional and mental health problems (e.g., isolation, anxiety, frustrations, and stress) that emerged in this process $[15,17]$. Furthermore, campus quarantine and management became crucial issues in relation to university operation, and the reduction of university finances was also raised as an important issue. In particular, because university finances have been reduced due to the COVID-19, many universities have reduced spending and staff and faculty to overcome financial difficulties $[37,38]$. These problems indicate that COVID-19 has broadly affected not only education at universities but also university operation, facility utilization, and manpower management.

Moreover, most of these studies analyzed cases of individual countries or universities $[20,30,31]$. These studies have the advantage of being able to understand how each country has responded during the COVID-19 pandemic, which can be beneficial because countries can share information and strategies among each other for responding to COVID-19. 


\subsection{Status of COVID-19 in Korea}

The first case of COVID-19 in Korea was documented in late January of 2020. As in many other countries, it has experienced several different mass spread events and new cases continue to be reported to this day. The Korea Disease Control and Prevention Agency (KDCA) differentiates the distinct phases of the COVID-19 spread as follows [39].

The first phase spans about a month from the first documented case on 20 January 2020 , which is believed to have originated from an international traveler carrying the virus. The second phase is from late February to early May where the first mass spread took place. A total of 10,774 cases were reported with the daily average of 138.1, and a large number of them concerned younger people. During the third phase from early May to mid-August, the mass spread at the beginning of the phase was followed by smaller-scale and spontaneous group infections in and near the capital city of Seoul. With an average of 39.3 new cases per day, the infection rate was relatively tame compared to the period prior. The fourth phase spanned from mid-August to mid-November, when religious institutions, protests, and community facilities in the capital region became a hotbed of infection which then spread to other regions of the country. A total of 13,282 cases were reported along with a high number of severe and fatal illnesses due to the large proportion of the elderly among the infected. The fifth phase is from mid-November to late December, and this is when the infection rate that had been previously controlled at around 100 cases per day skyrocketed tenfold to about 1000 per day following the third mass spread event in December, with the high infection rate continuing until the end of the phase. The main causes of the spread of COVID-19 at the national scale are believed to be the increased number of carriers who have mild to no symptoms themselves, common risk factors of the Winter season (e.g., increased indoor activities, insufficient ventilation, overall environment more conducive to the survival of the virus, etc.), and easing of social distancing restrictions (e.g., less control over meetings, events, and traveling, etc.). The spread of COVID-19 continued into 2021, and despite the distribution of vaccines from February 26, the infection rate shows no sign of subsiding [40].

\subsection{Government Responses to COVID-19}

The Ministry of Education was quick to respond to the pandemic. The initial spread of the virus from mid-February called for an immediate response since the Spring semester begins on March 2nd every year for all schools in Korea. Guidelines for College Academic Operations in Response to the New Coronavirus Disease [41] published by the Ministry of Education provided instructions for fulfilling academic requirements with a reduced number of lectures, recommended not penalizing absence due to health concerns, suggested placing new and transfer students on leave, and offered information on tuition payment deadlines and refund criteria. Expecting interruptions to activities on campus due to COVID-19, the guidelines called on college administrations to spread out classes to early mornings, night time, weekends, and holidays, utilize remote education, and condense curricula into a shorter time span. It also removed restrictions on the maximum number of remote classes that can be offered-which used to be capped at $20 \%$ of all class offerings before.

On 1 March, a day before the schools were scheduled to open for the Spring semester, the government enacted Codes on the Establishment and Operation of College and International Student Support Group in Response to COVID-19 [42]. This new support group was tasked with examining the current status of international students from China, sharing legal standing information on international students from the Ministry of Justice with college administrators, establishing a database on foreigners entering the country, including their region of origin and place of departure, and collecting other statistical data. It was also responsible for ensuring cooperation between local governments and college administrations, cataloguing local government assistance to colleges, examining each college's level of preparedness for the pandemic, and publishing and advertising a set of instructions in case of emergency. 
The Spring semester was ultimately postponed, and on 2 March the Ministry of Education published a comprehensive series of COVID-19 response measures in Recommendations for Academic Operations in the Spring Semester of 2020 [43]. These measures included the cancellation of on-campus classes, use of remote and online classes, immediate implementation of appropriate administrative measures for academic operations, establishment of Advisory Council on the Operation of Remote Education established to support college administrations and ensure the quality of remote classes, and establishment of a joint task force comprising the Ministry of Education, Korean Council for University Education, and Korean Council for University College Education.

The Ministry has since implemented a series of measures for continued academic operation in higher education. Emergency Support Program for Contactless College Education [44] was announced on 31 July, and Support Plans for Digital-based Innovations in Higher Education [45] followed suit immediately at the beginning of the Fall semester. In addition, an amendment to Higher Education Act on 24 September took the following form: (i) it allowed the government to provide financial support for the institutions in case of disaster and other abrupt changes to the educational environment; (ii) it provided legal foundations for the waiver or reduction of tuition payment which had been the subject of controversy; and (iii) it established procedural foundations for remote classes based on electronic media that replaced on-campus classes in case of disaster. Table 1 below showcases legal and policy-based measures taken by the Ministry of Education.

Table 1. Ministry of Education's Responses to COVID-19.

\begin{tabular}{|c|c|}
\hline Date & Ministry's Measures \\
\hline 12 February 2020 & $\begin{array}{l}\text { Published Guidelines for College Academic Operations in Response to the New } \\
\text { Coronavirus Disease [41] }\end{array}$ \\
\hline 1 March 2020 & $\begin{array}{l}\text { Established Codes on the Establishment and Operation of College and } \\
\text { International Student Support Group in Response to COVID-19 [42] }\end{array}$ \\
\hline 2 March 2020 & $\begin{array}{l}\text { Published Recommendations for Academic Operations in the Spring Semester of } \\
\qquad 2020[43]\end{array}$ \\
\hline 31 July 2020 & Implemented Emergency Support Program for Contactless College Education [44] \\
\hline 9 September 2020 & Published Support Plans for Digital-based Innovations in Higher Education [45] \\
\hline 24 September 2020 & Amended Higher Education Act in light of the COVID-19 pandemic [46] \\
\hline 5 October 2020 & Published Ten Policy Goals for Future Education in the Post-Pandemic Era [47] \\
\hline 16 February 2021 & $\begin{array}{l}\text { Published Basic Plans for Supporting Remote Education for Disabled College } \\
\text { Students [48] }\end{array}$ \\
\hline 21 April 2021 & $\begin{array}{c}\text { Announced Plans to strengthen COVID-19 quarantine measures in educational } \\
\text { institutions across the country [49] }\end{array}$ \\
\hline
\end{tabular}

The Ministry's responses can be broadly categorized into three groups: legal/institutional measures, technological measures, and policies concerning academic operations. As for the legal/institutional measures, an amendment to Executive Order on the Implementation of Higher Education Act [46] allowed for a reduction in the length of a class by up to two weeks per year, and the aforementioned amendment to Higher Education Act outlined procedures for offering financial support to colleges during disaster, waiving or reducing tuition for the students adversely affected, and utilizing various remote education methods. Standards for the Operation of Remote Classes in Four-Year Colleges for the Spring Semester of 2020 was revised on 9 September to allow colleges to offer any number of remote classes instead of capping them at 20\% of all credits offered [45], College and International Student Support Group was installed, and Basic Plans for Supporting Remote Education for Disabled College Students [48] were published on 16 February. The government also announced changes to the criteria for the payment and refund of tuition, which had been an important issue for many students. 
In terms of technological measures, Support Plans for Digital-based Innovations in Higher Education [45] published on 9 September designated Remote Education Support Centers in all ten regions of the country and offered KRW 12.8 billion to help set up Learning Management Systems (LMSs) and necessary devices for remote education in 2020. In addition, the government pledged KRW 100 billion in emergency financial support to improve the remote class environment in colleges, paid KRW 41.2 Billion to hire 4200 online class assistants, and utilized the budget for the College Innovation Support Program to support the construction of infrastructure for remote education. The government also promulgated Executive Order on the Operation of Remote Classes in Four-Year Colleges [50] to improve the quality of remote instruction.

On academic operations, on-campus classes were cancelled and students were to take classes at home via remote, assignment-based, and other options until the COVID-19 situation stabilized. The government also called on college administrations to be flexible in operating their curricula. The temporal patterns of COVID-19 spread and corresponding measures taken by the Ministry of Education are shown in Figure 1 below.

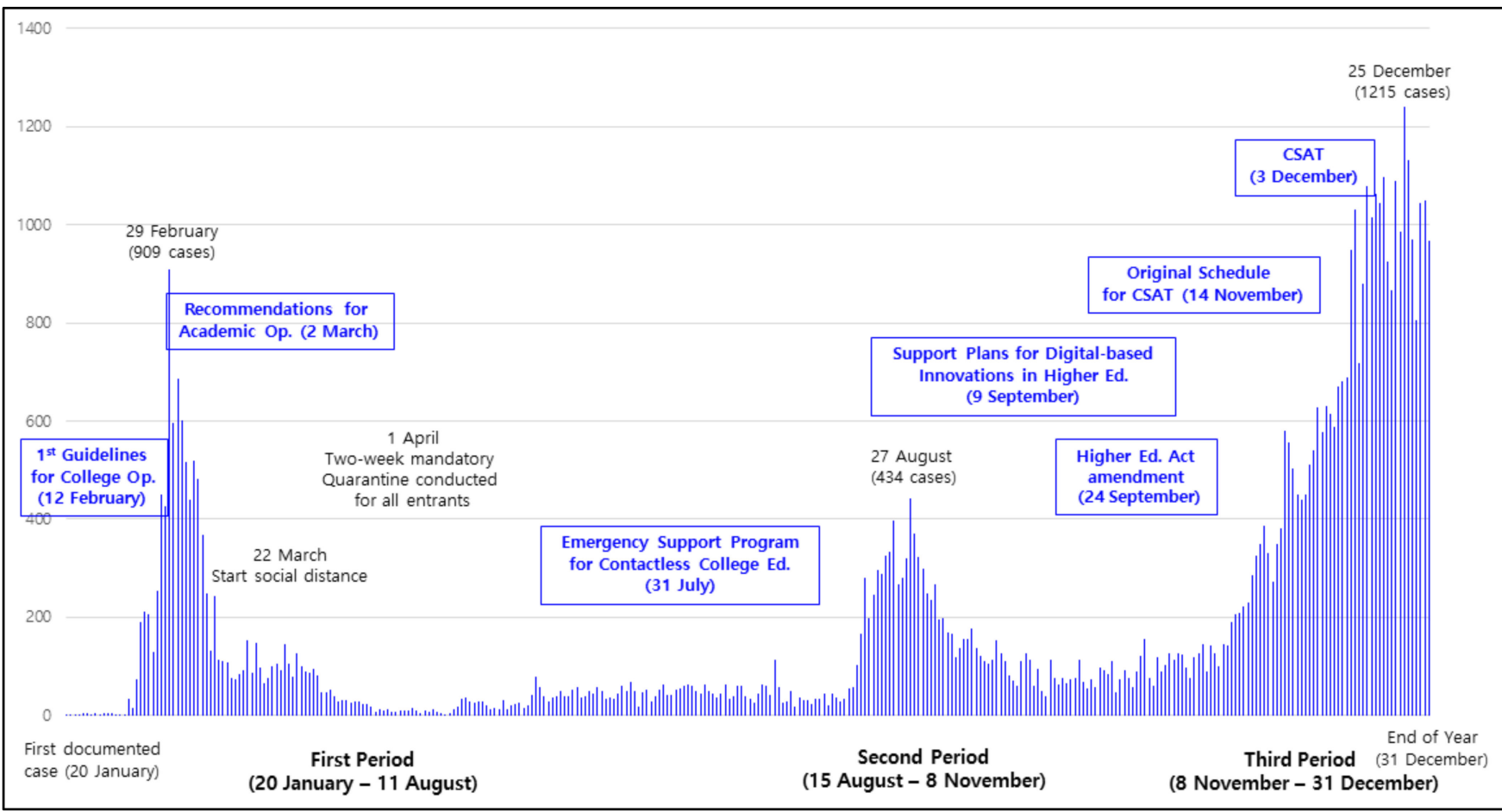

Figure 1. Spread of COVID-19 and Responses by the Ministry of Education in Korea. Source: Authors created based on the data from KDCA and information from the Ministry of Education.

\subsection{College-Level Responses to COVID-19}

In addition to government policies, college administrations also took part in several measures in accordance with those of the Ministry of Education [41-49]. These efforts took the form of: (i) revising internal codes to continue offering educational services during the COVID-19 disaster; (ii) institutional improvement such as removing the cap on the maximum number of remote classes offered; (iii) technological responses including the installation of LMSs and remote education infrastructure, expansion of remote class offerings, and establishment of systematic procedures to maintain quality of education in remote classes; (iv) flexible academic operations such as refraining from offering oncampus classes, making remote or otherwise at-home classes the new norm, and making adjustments to curved grading policy; (v) refunding tuition, expansion of scholarship opportunities, and other financial measures; and (vi) establishing and advertising standard operating procedures for on-campus and in-dormitory activities in response to COVID-19. 


\subsection{Reviewing Existing Research on Higher Education during the COVID-19 Pandemic in Korea}

As evidenced by the popularized term online semester, a vast majority of scholarly work on higher education during the COVID-19 pandemic has focused on the online aspect of education, such as contactless classes. Y. Lee and D. Shin [22] examined the current status of online classes among Korean colleges during the pandemic and identified the level of preparedness on the instructors' part as well as their familiarity with online communication devices as notable factors that affected the quality of online education. J. Jung [23] investigated college students' prior experience with online classes and their expectations and argued for a change in class procedures to fully reflect the contexts of contactless classes in order to improve the quality of college education amid COVID-19. J. Lee et al. [24] called for a change of paradigm so that online classes are considered a full-fledged mode of universal and standard education instead of a partial, temporary solution. Most of the research arguing for the expansion of online class opportunities focused on the positive aspects of such form of education. However, maximizing the educational effect of online classes requires ample preparations in terms of institutions and infrastructure, instructors' willingness to adapt to the new environment, and development of self-motivated methods of studying.

Some of the existing research has also touched on some uniquely Korean aspects of the issue. H. Shin, et al. [25] analyzed the controversy over refunding tuition as a form of decision-making paradox and called for the reconsideration of the government's stance on tuition that had been frozen for over ten years. Moreover, Feng and Park [26] discussed strategies to maintain quality education for the Chinese international students and to ensure their continued inflow at a time when foreign students' level of satisfaction with education services in Korea was diminishing. Institutions of higher education in Korea are faced with a multitude of challenges, such as raising the quality of classes, adjusting tuition, and operating programs designed for foreign students.

\section{Research Methods}

\subsection{Data Collection}

This paper utilized BIgKinds to collect news articles from 24 media outlets [51]. BIgKinds is a big data research solution offered by the Korea Press Foundation that contains about 70 million news contents from 54 different sources collected from 1990 and onward.

We first selected nine major newspapers with nationwide readership: Kyunghyang Shinmun, Dong-A Ilbo, Munhwa Ilbo, Seoul Shinmun, Segye Ilbo, JoongAng Ilbo, Chosun Ilbo, Hankyoreh, and Hankook Ilbo. We further selected nine regional newspapers, with the largest readership in each region, to adjust for geographical differences: Joongboo Ilbo, Kangwondomin Ilbo, Jungbu Maeil, Chungcheong Today, Maeil Shinmun, Busan Ilbo, Jeonbukdomin Ilbo, Jeonnam Ilbo, and Jemin Ilbo (See Table 2).

Table 2. Media Outlets Chosen for the Analysis.

\begin{tabular}{ccc}
\hline Type & No. of Sources & Selected Media Outlets \\
\hline National Newspapers & 9 & $\begin{array}{c}\text { Kyunghyang Shinmun, Dong-A Ilbo, } \\
\text { Munhwa Ilbo, Seoul Shinmun, Segye Ilbo, } \\
\text { JoongAng Ilbo, Chosun Ilbo, Hankyoreh, } \\
\text { Hankook Ilbo }\end{array}$ \\
Regional Newspapers & 9 & $\begin{array}{c}\text { Joongboo Ilbo, Kangwondomin Ilbo, } \\
\text { Jungbu Maeil, Chungcheong Today, Maeil } \\
\text { Shinmun, Busan Ilbo, Jeonbukdomin Ilbo, } \\
\text { Jeonnam Ilbo, Jemin Ilbo }\end{array}$ \\
\hline Business Newspapers & 2 & $\begin{array}{c}\text { Maeil Business, Korea Economic Daily } \\
\text { TV News Outlets }\end{array}$ \\
\hline
\end{tabular}


Moreover, two newspapers specializing in business news as well as four TV news outlets were also included in the analysis. We divided the year 2020 into three periods based on the periods divided by KDCA and the government policy responses: (i) first period from 20 January to 15 August, (ii) second period from 16 August to 8 November, and (iii) third period from 9 November to 31 December. The first period (20 January to 15 August), which involved the first to third phases as per KDCA, started from the first documented case of COVID-19 in Korea up to mid-August, which was just before the beginning of the massive second wave. During this period, the first mass spread was observed in May with continuous small-scale occurrences. This period also includes the first semester in colleges and most of summer vacation. The second period (16 August to 8 November), which is the fourth phase as per the KDCA, started at the end of the summer vacation and beginning of the fall semester but, more importantly, the beginning of the second mass spread of COVID-19 in Korea. Higher education institutions and the government had to prepare for the second semester, and thus, various policy measures were changed and implemented to deal with continuous COVID-19 pandemic. The third period (9 November to 31 December), which is the fifth phase as per KDCA, started from the beginning of the third wave of COVID-19, which involved the incidence of the highest cases in 2020. This period included important events, such as the CSAT, and the number of cases surged every day until the end of 2020 (see Figure 1).

We searched for news articles comprising the words COVID and College/University, which yielded a total of 8892 returns. We then removed any duplicates, personal details, announcements of events, and other articles without direct relevance to college education. This resulted in 2696 news articles-1184 for the first period, 629 for the second period, and 883 for the third period-being available for the present analysis. Any duplicate reports across any number of media outlets were condensed to a single article, and multiple broadcasts of the same news by a TV station were also considered to be just one entry. We also conducted cross-checking, where any article is removed from the source by consensus of two or more research associates.

\subsection{Method of Analysis}

This paper performs Topic Modeling to identify key topics in the collection of news articles and their changes across different periods. Based on the assumption that the composition of topics is a latent variable to be inferred, Topic Modeling uses a set of observed variables to infer the desired latent variables such as text structure. With this method, we are able to identify the proportion of topics in the collection of texts as well as the probability of each word to belong to any given topic [52].

Using NetMiner to perform Topic Modeling, we first filtered out all the words not in the noun form via the program's morphological analysis function. In addition, we also performed a series of pre-processing measures to make the analysis more reliable. First, all the words with the Term Frequency-Inverse Document Frequency (TF-IDF) value of 0.2 or less were removed. TF-IDF value for each word is calculated by retrieving the frequency of the term in each document and the scaled inverse fraction of the frequency of documents containing the term. A high TF-IDF value indicates a strong relationship between the term and the associated documents, whereas a low value tends to denote commonly used expressions that are less useful in distinguishing one document from another [53]. Some of the words removed by this procedure include college, virus, COVID, student, and spread for the first period, education, college, situation, process, COVID, school, and student for the second period, and college, situation, COVID, and student for the third period. We also removed stop words and single-word expressions whose meaning could not reliably pinpointed without further context.

Among different algorithms available for Topic Modeling, we use the popular Latent Dirichlet Allocation (LDA) algorithm. The LDA algorithm models the assignment of topics to each document and the allocation of words from each topic to the documents as two parameters to be inferred in the process of identifying the latent topics in the collection of 
text. For example, the topic assignment parameter $\mathrm{Z}_{\mathrm{d}, \mathrm{n}}$ depends on the per-document topic proportions $\theta_{\mathrm{d}}$ and the observed word $\mathrm{W}_{\mathrm{d}, \mathrm{n}}$ depends on the topic assignment parameter $Z_{\mathrm{d}, \mathrm{n}}$ and all topics $\beta_{1: \mathrm{k}}$, where $\theta$ : Per-document topic proportions; $\mathrm{z}$ : Per-word topic proportions; w: Observed word; $\beta$ : Topic parameter. The generative process and certain mathematical forms are statistically encrypted by the LDA algorithm $[52,54]$.

For the input parameters of $\alpha$ and $\beta$, we settled on $\alpha=12.5, \beta=0.01$, and the number of re-samplings at 1000 based on Finding Scientific Topics by Griffiths and Steyvers [55]. The recommended value for $\beta$ was originally 0.1 in the 2004 study but was later adjusted to 0.01 in a follow-up study in 2007 , and we reflected the latter in our analysis.

We also settled on the number of topics to be recovered via preliminary selection and validation process. In the preliminary selection stage, we refrained from mechanical and statistical methods and instead resorted to expert consensus based on the interpretability of words in each topic. Although words contain some degree of invariable quality, their exact meaning can change depending on contexts and we preferred the interpretability and validity of words over purely mechanical and statistical procedures which might yield uninterpretable results [56]. Hence, we first performed multiple Topic Modeling with the number of topics varying from two to twelve, extracted their topic maps, and consulted expert opinions to choose the number with a good combination of interpretability of words in their associated topics and differentiation between the topics in terms of word composition. This process yielded four as the optimal number of topics to be discovered in our analysis.

In order to validate the chosen number of topics, we assumed the results from LDA to be a clustering of keywords and documents and conducted an unsupervised leaning method of K-Means Clustering where we assessed whether the clusters contained keywords and documents with similar qualities [57]. K-Means Clustering is an algorithm that groups the given data points into $\mathrm{k}$ distinct clusters based on how close an observation is to the center of each cluster, thus clustering similar observations together. In order to evaluate the clustering performance, we calculated the Silhouette coefficients, which were 0.954, 0.946, and 0.944 for the three periods respectively. Since a Silhouette coefficient close to 1 indicates good clustering, we validated our chosen number of topics from all three coefficients being in close proximity to 1 .

\section{Analysis of the Results}

\subsection{Keywords Analysis}

The frequency of words that were most commonly found for each period in our analysis were presented in Table 3. During the first period from the first documented case of COVID-19 to August, some common keywords were class, online, education, lecture, tuition, school, and postponement. Other examples included Ministry of Education, international study, beginning of class, and beginning of semester. These keywords likely reflect the context where the Spring semester had to be postponed for about two weeks in most colleges following an initial spread of COVID-19 and online classes became a primary mode of education after schools and colleges closed. These circumstances also gave rise to a demand for tuition refund as students were not able to utilize on-campus facilities, services, and events.

The second period from August to early November featured many keywords associated with classes and college admissions. The former was driven by the beginning of the Fall semester on September 1 which prompted discussions on how to conduct future classes, and the latter primarily concerned the College Scholastic Ability Test (CSAT) as high schools began preparing their seniors for college admissions in the Fall. With the early admissions process beginning in October and CSAT scheduled for 3 December, a number of news outlets focused their attention on college admissions and CSAT. Other than class and CSAT, some other notable keywords for the period were online, test, assessment, application/support, test-taking, and admissions process. 
Table 3. Top Keywords for Each Period and Their Frequency.

\begin{tabular}{|c|c|c|c|c|c|c|}
\hline \multirow{2}{*}{ Category } & \multicolumn{2}{|c|}{ First Period } & \multicolumn{2}{|c|}{ Second Period } & \multicolumn{2}{|c|}{ Third Period } \\
\hline & Keyword & Frequency & Keyword & Frequency & Keyword & Frequency \\
\hline 1 & Class & 3381 & Class & 2114 & CSAT & 3886 \\
\hline 2 & Online & 2842 & CSAT & 1588 & Test-taking & 2998 \\
\hline 3 & Education & 2190 & Online & 960 & Test & 2197 \\
\hline 4 & Lecture & 2142 & Test & 856 & Education & 2139 \\
\hline 5 & Tuition & 1967 & Assessment & 835 & Confirmed case & 1724 \\
\hline 6 & School & 1900 & Application/Support & 828 & School & 1365 \\
\hline 7 & Postponement & 1446 & Test-taking & 808 & Quarantine & 1233 \\
\hline 8 & $\begin{array}{l}\text { Ministry of } \\
\text { Education }\end{array}$ & 1352 & Professor & 697 & Test location & 1133 \\
\hline 9 & Application/Support & 1349 & Remote & 671 & Class & 938 \\
\hline 10 & Process & 1221 & $\begin{array}{c}\text { Admissions } \\
\text { process }\end{array}$ & 668 & Region & 903 \\
\hline 11 & Region & 1206 & Society & 655 & Application/Support & 877 \\
\hline 12 & $\begin{array}{l}\text { International } \\
\text { Study }\end{array}$ & 1174 & $\begin{array}{l}\text { Ministry of } \\
\text { Education }\end{array}$ & 576 & Society & 827 \\
\hline 13 & Situation & 1153 & Region & 568 & Process & 816 \\
\hline 14 & Professor & 1153 & Employment & 567 & Online & 768 \\
\hline 15 & $\begin{array}{l}\text { Beginning of } \\
\text { class }\end{array}$ & 1078 & Interview & 554 & Assessment & 758 \\
\hline 16 & New & 1064 & Lecture & 526 & Infection & 742 \\
\hline 17 & $\begin{array}{l}\text { Beginning of } \\
\text { semester }\end{array}$ & 955 & Quarantine & 509 & Test Application & 689 \\
\hline 18 & Test & 913 & $\begin{array}{c}\text { Early } \\
\text { admissions }\end{array}$ & 490 & Scholastic & 689 \\
\hline 19 & Plan & 846 & $\begin{array}{c}\text { College } \\
\text { Admissions }\end{array}$ & 466 & Center & 666 \\
\hline 20 & China & 829 & Semester & 450 & Spread & 617 \\
\hline
\end{tabular}

The third period was marked with an increased emphasis on CSAT as it included the test date of December 3. Some prominent keywords from this period included CSAT, test-taking, test, education, and other words related to CSAT as well as some words that reflected concerns about holding a large-scale event such as confirmed case, quarantine, test location, and process.

\subsection{Analysis of Topics}

We have identified the main topics from each period and extracted top ten words with the highest weights for each topic. A period-by-period analysis is given below. 


\section{A. Analysis on the First Period}

The main topics for the first period can be interpreted as remote classes, tuition refund, returning international students from China, and normalization of college education (See Table 4). After the first documented case in January and subsequent spread of COVID19 in February, an issue that grabbed public attention was whether colleges would be able to continue offering classes as planned. Since most schools open for the Spring semester on 2 March in Korea, there was much discussion on the option of postponing the semester, which prompted public discourses on relevant issues. As the continued spread of COVID-19 forced colleges to adopt full-fledged remote classes, news articles tended to address the issue of how to effectively conduct classes in this new environment.

Table 4. Extracted Topics and Keywords in the First Period.

\begin{tabular}{|c|c|c|c|c|}
\hline Category & Topic 1 & Topic 2 & Topic 3 & Topic 4 \\
\hline Topic & Remote Classes & Tuition Refund & $\begin{array}{l}\text { Returning Chinese } \\
\text { Students }\end{array}$ & $\begin{array}{l}\text { Normalization of } \\
\text { College Edu. }\end{array}$ \\
\hline 1 & Class & Tuition & Postponement & Education \\
\hline 2 & Online & Ministry of Education & Region & Application/Support \\
\hline 3 & Lecture & Application/Support & International Study & Professor \\
\hline 4 & School & Situation & Beginning of Semester & College President \\
\hline 5 & Process & Government & New & Society \\
\hline 6 & Professor & Return & Plan & College \\
\hline 7 & Beginning of semester & Scholarship & China & Employment \\
\hline 8 & Test & Demand & Chinese & Participation \\
\hline 9 & Remote & Refund & Cancellation & Utilization \\
\hline 10 & Assessment & Payment & Entering Korea & Program \\
\hline Proportions (\%) & 36 & 24 & 24 & 16 \\
\hline
\end{tabular}

As international travel faced increased restrictions due to the spread of COVID-19, international students became the subject of yet another important issue, which is represented by Topic 3 . More than $50 \%$ of all inbound international students to Korea are Chinese, and colleges were eager to find out whether they could continue accepting students from China under the new restrictions put in place by the Chinese government as well as how to respond to an influx of students from the country in which the disease was believed to have originated. Inability to accept Chinese students would have placed a large financial burden on a number of colleges that relied upon their tuition for their annual budget. This concern likely drove the high frequency of some keywords such as Chinese, entering Korea, cancellation, postponement, and international study.

The issue of tuition refund as shown in Topic 2 was an important matter to many students. As the number of new cases reached a new record in mid-March-as shown in Figure 1-colleges relied increasingly on contactless classes which led to some students expressing discontent. As tuitions charged by colleges in Korea are some of the highest in the world [58], the lack of on-campus classes combined with the inability to use campus facilities gave rise to a demand for tuition refund to compensate for the loss of benefits. On the other hand, college administrations found it difficult to accommodate this demand as their basic operations are still funded by tuition payments. The frustrated students then instead took the matter to the Ministry of Education coordinating college administrations 
and publicized tuition refund or reduction as a social issue. Tuition, refund, scholarship, Ministry of Education, government, and other relevant terms included under Topic 2 represent this issue well.

The topic of normalization of college education appeared primarily during the late stage of the first period when the infection rate seemed to be under control. As COVID-19 spread events tended to be restricted to certain regions and smaller groups, college administrations were cautiously optimistic about resuming normal operations. As the summer break rolled in from late June and the infection rate stabilized, colleges began discussions on future measures in the post-pandemic era and the resumption of normal curricula. Some terms such as education, professor, college president, and college can be thought of as representing the planned efforts of these actors to return to normal operations. Some other terms including education, participation, and program seem to indicate anticipation of a higher level of student activities.

\section{B. Analysis on the Second Period}

The extracted topics from the second period can be described as CSAT preparations, contact and contactless classes, preparations for early admissions, and supporting job market candidates (See Table 5). This period begins in mid-August when preparations were being made for the upcoming Fall semester in September. College admissions also take place in the same period in Korea, with early admissions beginning in October and CSAT typically being held in early to mid-November. College entrance exams are considered one of the most important issues in the country's education and thus CSAT commands widespread public attention. The continued spread of COVID-19 had already forced the government in April to postpone CSAT from November 14 to December 3. Since CSAT is a high-visibility, large-scale event that affects all regions, ample preparations had to be made and parents and the general public had been asking for precautions in case of potential mass outbreak ever since the early Fall season. Hence CSAT, test, test-taking, quarantine, and school attendance became some of the top keywords during this period.

Table 5. Extracted Topics and Keywords from the Second Period.

\begin{tabular}{|c|c|c|c|c|}
\hline Category & Topic 1 & Topic 2 & Topic 3 & Topic 4 \\
\hline opic & Preparations for CSAT & $\begin{array}{l}\text { Preparations for Early } \\
\text { Admissions }\end{array}$ & $\begin{array}{c}\text { Contact and Contactless } \\
\text { Classes }\end{array}$ & $\begin{array}{c}\text { Supporting Job Market } \\
\text { Candidates }\end{array}$ \\
\hline 1 & CSAT & Assessment & Class & Online \\
\hline 2 & Test & Application/Support & Online & Application/Support \\
\hline 3 & Test-taking & Admissions Process & Professor & Society \\
\hline 4 & Remote & Interview & Remote & Region \\
\hline 5 & Ministry of Education & Early admissions & Lecture & Employment \\
\hline 6 & Quarantine & College Entrance Exam & Semester & Era/Age \\
\hline 7 & Prep School & Timetable & Contact & College \\
\hline 8 & Confirmed Case & Recruitment & Thinking & Program \\
\hline 9 & School Attendance & Standard & Scholarship & Company \\
\hline 10 & Distance & College Admissions & Tuition & Participation \\
\hline Proportions (\%) & 30 & 26 & 28 & 16 \\
\hline
\end{tabular}


Korean colleges typically employ a dual-track system for admissions: regular admissions rely primarily on CSAT and early admissions select promising students before CSAT takes place. Since each college is allowed to set their own admissions standards for the latter, it is less dependent on government-run assessment tests and thus a large number of students apply for early admissions. In addition to evaluating the applicants via essay-writing tasks and interviews, colleges also review their history of extracurricular activities as an important criterion. As COVID-19 restricted options for such activities, however, ensuring fairness in the early admissions process became an important issue. As a result, the topic of preparations for early admissions includes keywords such as assessment, criterion, admissions process, interview, and early admissions.

As the country came to the realization that the pandemic was here to stay longer than originally anticipated, long-term preparations had to be made accordingly. While many of the official measures taken in the Spring semester were emergency responses in nature, a more systematic approach was devised for the Fall semester based on the experience from the preceding one. Colleges began to consider offering a combination of contact and contactless classes instead of going fully online, and various measures were taken to raise the quality of the classes offered. Topic 3 showcases such attempts, with the keywords of online, class, contact, thinking, and professor denoting this new emphasis on different formats of college education.

The fourth topic of supporting job market candidates is related to the corporate recruitment season in the latter half of the year. Many companies in Korea typically recruit near the end of the year to allow college seniors to immediately start working once they graduate. However, not only did the spread of COVID-19 significantly limit academic activities, but market uncertainties also drove many companies to cancel planned recruitment or reduce its scope drastically. As job openings became increasingly scarce, colleges attempted to support their job market candidates in a multitude of ways. Employment, application/support, company, participation, program, and other related keywords included in Topic 4 exemplify such undertakings.

\section{Analysis on the Third Period}

The main topics for the third period are CSAT and college-specific exams, quarantine on campus, social relations on campus, and supporting job market candidates (See Table 6). This period witnessed a worsening of the COVID-19 pandemic from mid-November and includes the date of CSAT on December 3. Hence the biggest issue during this period was CSAT and other college-specific entrance exams. With hundreds of thousands of students flocking to designated test centers for CSAT, the government as well as the public turned their attention to this large-scale event. Some keywords belonging to Topic 3 include test location, test-taking, interview, test application, assessment, and test questions reflecting this emphasis on CSAT and its quarantine procedures.

During this period, becoming completely COVID-free seemed increasingly like a distant prospect and the pandemic became part of the new normal life, where the government and colleges adjusted their expectations in accordance with the new reality instead of undertaking drastic measures. Topics 1 and 4 represent this tendency well. For example, school, learning, lecture, class, person, thinking, and education are some of the keywords belonging to the topic of social relations on campus, and they indicate continued discussions on effective ways to offer classes and provide educational services in this new era.

While quarantine on campus has been a longstanding subject of discussion, the dramatic rise in the number of confirmed cases with the third mass spread event prompted further discourses in this regard. As shown in Figure 1 above, infection rates began to climb from mid-November and eventually led to an unprecedented mass spread event in the country. People were left in a state of shock as the number of new cases reached 1000 per day and more, and the infection rate reached its peak in late December. Since a large number of the newly infected were college students, this directed public attention to the issue of quarantine on campus. Several keywords belonging to this topic were infection, life, spread, medical treatment, quarantine, and confirmed case. 
Table 6. Extracted Topics and Keywords in the Third Period.

\begin{tabular}{|c|c|c|c|c|}
\hline Category & Topic 1 & Topic 2 & Topic 3 & Topic 4 \\
\hline Topic & $\begin{array}{l}\text { Social Relations on } \\
\text { Campus }\end{array}$ & Support for Job Searching & $\begin{array}{c}\text { CSAT \& College-specific } \\
\text { Exams }\end{array}$ & Quarantine on Campus \\
\hline 1 & Education & Education & CSAT & Confirmed case \\
\hline 2 & School & Region & Test-taking & Quarantine \\
\hline 3 & Class & Application/Support & Test & Infection \\
\hline 4 & Society & Process & Test location & Spread \\
\hline 5 & Online & Online & Assessment & Ministry of Edu. \\
\hline 6 & Learning & Center & Scholastic & Life \\
\hline 7 & Thinking & College & Test Application & Distance \\
\hline 8 & Lecture & Employment & Academic Year & Examination \\
\hline 9 & Space & Business & Interview & Treatment \\
\hline 10 & Person/People & Innovation & Test Questions & Hospital \\
\hline Proportions (\%) & 19 & 17 & 40 & 24 \\
\hline
\end{tabular}

\section{Conclusions and Implications}

COVID-19 represented one of the biggest and unexpected crises that befell humanity in the 21st Century, and it spared no one in the world regardless of space and time. The debilitating impact of the disease was felt across political, economic, social, cultural, and many other aspects of human lives. Fortunately, the government of Korea was quick to respond to COVID-19 with various policy measures and the public adhered to the guidelines well, which contributed to the relative success of the country in avoiding the worst possible outcome from the pandemic. The success is further exemplified in the area of higher education where colleges have continued to operate without severe interruption since the beginning of the pandemic. In this context, this paper analyzed the main issues that emerged regarding higher education in this country from the first documented case of COVID-19 to the end of the year 2020. In doing so, it identified several prominent issues during the three different periods of the pandemic and discussed the implications of its findings on education policy.

The paper reviewed policy measures undertaken by the government and college administrations and examined prominent public discourses recovered from media reports. First, several different topics along with their associated keywords presented themselves during the pandemic, with the college admissions often taking the spotlight. The sudden spread of COVID-19 and the upcoming Spring semester meant that in the first period, the primary topics like many other countries $[1,3,32]$ were the postponement of the semester and returning international students. They were then followed by discussions on online classes, and then by cautiously optimistic prospects of returning to the pre-pandemic format of college education when the number of new cases seemed to stabilize. On the other hand, much of the second and third period was dominated by the topic of college admissions. The second period saw increased visibility of the early admissions process and preparations for, and the administration of, the nationwide event of CSAT. This tendency was also replicated in the third period that included 3 December, the date on which CSAT was held. CSAT, college-specific exams, and quarantine on campus were at the forefront of public attention during this period. CSAT and other issues in college admissions had 
already commanded immense interest even before the pandemic, and it continued to be an important topic as the country struggled with the disease.

Second, tuition-related issues started to surface from the first period itself. Although universities were not entirely closed like many other countries, students had limited access to campus facilities, and classes were held online; therefore, there was a backlash against charging students the normal fees. The problems related to university finances were also observed in other countries during the COVID-19 pandemic. Numerous studies have discussed regarding the difficulties of college education because of the COVID-19 pandemic, and there have been reports of reducing expenses and the number of faculty members to overcome financial difficulties $[39,40]$. Furthermore, a systemic simulation of financial difficulties was also attempted [21]. However, in South Korea, students' demands for tuition reimbursement were more prominent than the financial difficulties of universities because, as discussed previously, the tuition paid by students in Korea is very high.

Third, Korean universities, like other universities in the world, suffered substantially because of the COVID-19 outbreak in 2020. However, factors that threaten the sustainability of Korean universities have persisted for the past decades. Due to the decrease in the school-age population, the number of university students decreased, and therefore, the financial difficulties of universities whose primary source of income was tuition became difficult. To reduce the number of higher education institutions and ensure the quality of university education, the government has been restructuring for the past two decades through university evaluation and has attempted to expel universities that do not meet the standards [59]. Under these circumstances, the outbreak of COVID-19 has placed universities under a direct threat. The additional threat to sustainability of the universities is well-documented in the initial topics presented in this study. In the case of the return of Chinese students (topic 3), which was observed during the first period, there was a concern about the expected decrease in tuition income because foreign students did not return. Furthermore, the efforts to continue online classes (topic 1) without closing schools and normalize university education (topic 4 ) reflect the situation for minimizing the request for tuition refund (topic 2) and preventing student dropouts. Furthermore, the issues related to college admissions that are continuously observed in the second and third periods can be attributed to the fact that not only the general public and parents but also the university recognized the discussion related to university admission as an important issue for recruiting students. In fact, the enrollment status of students entering the school year for 2021, which appeared in February 2021, was shocking [60]. Many colleges and universities failed to recruit the number of enrolled students as per their expectations. The fear of the shortage of student enrollment in near future was actually realized. Universities are now faced with the double challenges of surviving and sustaining from two huge waves: a continuing decline in school-age populations and a sudden drop out of students because of the COVID-19 pandemic. The big data analysis of news articles has shown its merit by successfully identifying the issues that the public was most interested in, although it has also shown empirically that government and college-level responses to combat COVID-19 had limited visibility among media reports. Both of these actors played an important role in ensuring uninterrupted operation of the country's higher education system through prompt and appropriate crisis management. The Ministry of Education enacted or amended relevant laws and regulations and college administrations also adjusted their internal codes to provide procedural foundations for crisis management. Quarantine on campus was given priority, school openings were delayed, and the academic calendar was adjusted according to the guidelines published by the government that increased public awareness and recommended appropriate measures. The continuation of college academic operations in 2020 was only possible thanks to these efforts. Unfortunately, however, our analysis suggests that most of the news articles collected from prominent media outlets fail to capture these crucial contributions. This likely shows that the media was primarily concerned with covering the issues that commanded the interest of parents 
and the general public instead of the efforts of the government and colleges to normalize higher education amid the pandemic.

In this context, we suggest that for a more fine-tuned analysis on government and college-level responses, researchers would need to consult official statements from the Ministry of Education as well as from each college and collect additional information from their websites for further examination. These additional sources of data would provide extra insight into the specific details of the measures undertaken by the government and college administrations. It is self-evident that it was thanks to the timely and appropriate measures taken by the government and college administrations that the country was able to provide higher education in at least partial capacity. In addition to the media's role in reporting issues of public interest, there also is a need for continued research and discussion on higher education amid COVID-19 to help effect actual results from various policy efforts.

Author Contributions: Conceptualization and research design, J.K. and S.P. (Seungsu Paek); First draft preparation, J.K. and S.P. (Seoyoon Park); Data preparation and analysis, S.P. (Seoyoon Park) and J.P.; Review and Final draft, J.K., S.P. (Seungsu Paek) and S.P. (Seoyoon Park); Editing of the final draft, S.P. (Seungsu Paek); Review and revision of the final draft, J.K., S.P. (Seungsu Paek), S.P. (Seoyoon Park) and J.P. All authors have read and agreed to the published version of the manuscript.

Funding: This research received no external funding.

Institutional Review Board Statement: Not applicable.

Informed Consent Statement: Not applicable.

Data Availability Statement: Data available in a publicly accessible repository that does not issue DOIs Publicly available datasets were analyzed in this study. This data can be found here: https: / / www.bigkinds.or.kr/ (Accessed 21 April 2021).

Conflicts of Interest: The authors declare no conflict of interest.

\section{References}

1. International Association of Universities (IAU). IAU Global Survey on the Impact of COVID-19 on Higher Education around the World; IAU: Paris, France, 2020. Available online: https://www.iau-aiu.net/IAU-Global-Survey-on-the-Impact-of-COVID-19 -on-Higher-Education-around-the (accessed on 22 April 2021).

2. UNESCO. UNESCO's Support: Educational Response to COVID-19; UNESCO: Paris, France, 2021. Available online: https: / / en.unesco.org/covid19/educationresponse/support (accessed on 22 April 2021).

3. Quacquarelli Symonds. The Impact of The CoronaVirus on Global Higher Education. Available online: http://info.qs.com/rs/33 5-VIN-535/images/The-Impact-of-the-Coronavirus-on-Global-Higher-Education.pdf (accessed on 22 April 2021).

4. Alonso-García, M.; Garrido-Letrán, T.; Sánchez-Alzola, A. Impact of COVID-19 on educational sustainability. Initial perceptions of the university community of the University of Cádiz. Sustainability 2021, 13, 5938. [CrossRef]

5. Chu, A.; Liu, C.; So, M.; Lam, B. Factors for sustainable online learning in higher education during the COVID-19 pandemic. Sustainability 2021, 13, 5038. [CrossRef]

6. Mo, C.; Hsieh, T.; Lin, C.; Jin, Y.; Su, Y. Exploring the critical factors, the online learning continuance usage during COVID-19 pandemic. Sustainability 2021, 13, 5471. [CrossRef]

7. Toader, T.; Safta, M.; Titirișcă, C.; Firtescu, B. Effects of digitalisation on higher education in a sustainable development framework-Online learning challenges during the COVID-19 pandemic. Sustainability 2021, 13, 6444. [CrossRef]

8. Petchamé, J.; Iriondo, I.; Villegas, E.; Riu, D.; Fonseca, D. Comparing face-to-face, emergency remote teaching and smart classroom: A qualitative exploratory research based on students' experience during the covid-19 pandemic. Sustainability 2021, $13,6625$. [CrossRef]

9. Ali, W. Online and remote learning in higher education institutes: A necessity in light of COVID-19 pandemic. High. Educ. Stud. 2020, 10, 16-25. [CrossRef]

10. Zamora-Antuñano, M.; Rodríguez-Reséndiz, J.; Rodriguez Segura, L.; Cruz Pérez, M.; Corro, J.A.; Paredes-Garcia, W.; RodríguezReséndiz, H. Analysis of emergency remote education in COVID-19 crisis focused on the perception of the teachers. Sustainability 2021, 13, 3820. [CrossRef]

11. Gherheș, V.; Stoian, C.; Fărcașiu, M.; Stanici, M. E-learning vs. face-to-face learning: Analyzing students' preferences and behaviors. Sustainability 2021, 13, 4381. [CrossRef]

12. Vojteková, J.; Tirpáková, A.; Gonda, D.; Žoncová, M.; Vojtek, M. GIS distance learning during the COVID-19 pandemic (students' perception). Sustainability 2021, 13, 4484. [CrossRef] 
13. Aristovnik, A.; Keržič, D.; Ravšelj, D.; Tomaževič, N.; Umek, L. Impacts of the COVID-19 pandemic on life of higher education students: A global perspective. Sustainability 2020, 12, 8438. [CrossRef]

14. Cicha, K.; Rizun, M.; Rutecka, P.; Strzelecki, A. COVID-19 and higher education: First-year students' expectations toward distance learning. Sustainability 2021, 13, 1889. [CrossRef]

15. Elmer, T.; Mepham, K.; Stadtfeld, C. Students under lockdown: Comparisons of students' social networks and mental health before and during the COVID-19 crisis in Switzerland. PLoS ONE 2020, 15, e0236337. [CrossRef] [PubMed]

16. Alghamdi, A.A. Impact of the COVID-19 pandemic on the social and educational aspects of Saudi university students' lives. PLoS ONE 2021, 16, e0250026. [CrossRef] [PubMed]

17. Liu, X.; Liu, J.; Zhong, X. Psychological state of college students during COVID-19 epidemic. SSRN 2020. [CrossRef]

18. Navarro-Espinosa, J.; Vaquero-Abellán, M.; Perea-Moreno, A.; Pedrós-Pérez, G.; Aparicio-Martínez, P.; Martínez-Jiménez, M. The higher education sustainability before and during the COVID-19 pandemic: A spanish and ecuadorian case. Sustainability 2021, 13, 6363. [CrossRef]

19. Casacchia, M.; Cifone, M.G.; Giusti, L. Distance education during COVID 19: An Italian survey on the university teachers' perspectives and their emotional conditions. BMC Med. Educ. 2021, 21, 335. [CrossRef]

20. Van Schalkwyk, F. Reflections on the public university sector and the covid-19 pandemic in South Africa. Stud. High. Educ. 2020, 44-58. [CrossRef]

21. Pavlov, O.; Katsamakas, E. COVID-19 and financial sustainability of academic institutions. Sustainability 2021, 13, 3903. [CrossRef]

22. Lee, Y.; Shin, D. An investigation of the implementation of online classes in the Untact Era caused by the COVID-19 pandemic. J. Curric. Eval. 2020, 23, 39-57. [CrossRef]

23. Jung, J.-Y. A study on the method for quality management of higher education in the Post Corona. Educ.Res. Tomorrow 2020, 33, 171-192. [CrossRef]

24. Lee, J.-Y.; Sung, E.; Lee, J.; Lim, K.-Y.; Han, S. Challenges and tasks facing online classes during the COVID-19 pandemic. J. Educ. Tech. 2020, 36, 671-692. [CrossRef]

25. Shin, H.; Kwon, G.; Hong, B. Analysis on the paradox effects during college tuition policy change: Focusing on the tuition refund conflict due to COVID-19. J. Politics Educ. 2021, 28, 63-96.

26. Feng, D.; Park, J. Globalization strategy of universities in korea in the post COVID-19 Era-Focused on strategy of improvement in education for chinese students in the post COVID-19 era. Chin. Stud. 2020, 85, 305-329.

27. Choi, H.; Chung, S.-Y.; Ko, J. Rethinking teacher education policy in ICT: Lessons from emergency remote teaching (ERT) during the COVID-19 pandemic period in Korea. Sustainability 2021, 13, 5480. [CrossRef]

28. Watermeyer, R.; Crick, T.; Knight, C.; Goodall, J. COVID-19 and digital disruption in UK universities: Afflictions and affordances of emergency online migration. High. Educ. 2021, 81, 623-641. [CrossRef]

29. Zawacki-Richter, O. The current state and impact of Covid-19 on digital higher education in Germany. Hum. Behav. Emerg. Technol. 2021, 3, 218-226. [CrossRef]

30. Agasisti, T.; Soncin, M. Higher education in troubled times: On the impact of Covid-19 in Italy. Stud. High. Educ. 2021, 46, 86-95. [CrossRef]

31. Liu, Y.; Zhang, Y.; Qiao, W.; Zhou, L.; Coates, H. Ensuring the sustainability of university learning: Case study of a leading chinese university. Sustainability 2020, 12, 6929. [CrossRef]

32. Joaquin, J.B.; Biana, H.T.; Dacela, M.A. The philippine higher education sector in the time of COVID-19. Front. Educ. 2020, 5, 576371. [CrossRef]

33. Nassr, R.M.; Aborujilah, A.; Aldossary, D.A.; Aldossary, A.A.A. Understanding education difficulty during COVID-19 lockdown: Reports on malaysian university students' experience. IEEE Access 2020, 8, 186939-186950. [CrossRef]

34. Alvarez-Risco, A.; Del-Aguila-Arcentales, S.; Rosen, M.A.; García-Ibarra, V.; Maycotte-Felkel, S.; Martínez-Toro, G.M. Expectations and interests of university students in COVID-19 times about sustainable development goals: Evidence from Colombia, Ecuador, Mexico, and Peru. Sustainability 2021, 13, 3306. [CrossRef]

35. Moorhouse, B.L.; Kohnke, L. Thriving or surviving emergency remote teaching necessitated by COVID-19: University teachers' perspectives. Asia Pac. Educ. Res. 2021, 30, 279-287. [CrossRef]

36. Mohmmed, A.O.; Khidhir, B.A.; Nazeer, A.; Vijayan, V.J. Emergency remote teaching during Coronavirus pandemic: The current trend and future directive at Middle East College Oman. Innov. Infrastruct. Solut. 2020, 5, 1-11. [CrossRef]

37. Bauman, D. A Brutal Tally: Higher Ed Lost 650,000 Jobs Last Year. Chron. High. Educ. 2021, 2, 5. Available online: https: //www.chronicle.com/article/a-brutal-tally-higher-ed-lost-650-000-jobs-last-year (accessed on 15 June 2021).

38. Wescott, D. Will Coronavirus Close Your College for Good? Chron. High. Educ. 2020, 3, 25. Available online: https://www. chronicle.com/article/will-coronavirus-close-your-college-for-good/ (accessed on 15 June 2021).

39. Korea Disease Control and Prevention Agency (KDCA). Current Status of COVID-19 Outbreak in Korea (31 December 2020); KDCA: Chungcheongbuk-do, Korea, 2020.

40. Korea Disease Control and Prevention Agency(KDCA). Current Status of COVID-19 Outbreak and Vaccination in Korea (3.18. Regular Briefing); KDCA: Chungcheongbuk-do, Korea, 2021.

41. Ministry of Education. Guidelines for College Academic Operations in Response to the New Coronavirus Disease; Ministry of Education: Sejong, Korea, 2020. 
42. Ministry of Education. Established Codes on the Establishment and Operation of College and International Student Support Group in Response to COVID-19; Ministry of Education: Sejong, Korea, 2020.

43. Ministry of Education. Published Recommendations for Academic Operations in the Spring Semester of 2020; Ministry of Education: Sejong, Korea, 2020.

44. Ministry of Education. Implemented Emergency Support Program for Contactless College Education; Ministry of Education: Sejong, Korea, 2020.

45. Ministry of Education. Support Plans for Digital-Based Innovations in Higher Education; Ministry of Education: Sejong, Korea, 2020.

46. Ministry of Education. Amended Higher Education Act in Light of the COVID-19 Pandemic; Ministry of Education: Sejong, Korea, 2020.

47. Ministry of Education. Ten Policy Goals for Future Education in the Post-Pandemic Era; Ministry of Education: Sejong, Korea, 2020.

48. Ministry of Education. Basic Plans for Supporting Remote Education for Disabled College Students; Ministry of Education: Sejong, Korea, 2021.

49. Ministry of Education. Plans to Strengthen COVID-19 Quarantine Measures in Educational Institutions across the Country; Ministry of Education: Sejong, Korea, 2021.

50. Ministry of Education. Executive Order on the Operation of Remote Classes in Four-Year Colleges; Ministry of Education: Sejong, Korea, 2020.

51. Available online: https:/ / www.bigkinds.or.kr/ (accessed on 5 April 2021).

52. Blei, D.M. Probabilistic topic models. Commun. ACM 2012, 55, 77-84. [CrossRef]

53. Ramos, J. Using TF-IDF to determine word relevance in document queries. Proc. First Instr. Conf. Mach. Learn. 2003, 242, 29-48.

54. Blei, D.M.; Ng, A.Y.; Jordan, M.I. Latent dirichlet allocation. J. Mach. Learn. Res. 2003, 3, 993-1022.

55. Griffiths, T.L.; Steyvers, M. Finding scientific topics. Proc. Natl. Acad. Sci. USA 2004, 101 (Suppl. 1), 5228-5235. [CrossRef]

56. DiMaggio, P.; Nag, M.; Blei, D. Exploiting affinities between topic modeling and the sociological perspective on culture: Application to newspaper coverage of US government arts funding. Poetics 2013, 41, 570-606. [CrossRef]

57. Mehta, V.; Caceres, R.S.; Carter, K.M. Evaluating topic quality using model clustering. In Proceedings of the 2014 IEEE Symposium on Computational Intelligence and Data Mining (CIDM), Orlando, FL, USA, 9-12 December 2014.

58. Organisation for Economic Co-Operation and Development. Education at a Glance 2020: OECD Indicators; OECD: Paris, France, 2020. [CrossRef]

59. The Ministry of Education. Announcement of Higher Education Restructuring Plan; Ministry of Education: Sejong, Korea, 2014.

60. Maeil Business. "School-Age Population Decline" Hits Universities across the Country. Universities Were Unable to Fill the Freshman Quota. Available online: https://www.mk.co.kr/news/society/view/2021/03/201261/ (accessed on 15 June 2021). (In Korean) 